\title{
ANALISIS SERAPAN KEBISINGAN \\ DENGAN PEMASANGAN ROCK WOOL KETEBALAN 5 CM
}

\author{
Haryono S Huboyo, Mochtar Hadiwidodo *), Suhardi **) \\ email : huboyo@undip.ac.id
}

\begin{abstract}
The noise affects to working quality at the same degree as those to workforce and people health, therefore, appropriate noise control is indispensable. This study is aimed at evaluating of rockwool (5cm) absorption coefficient and analyzing its effectivity on noise control. The room for simulation is equipped with known noise source. In this case a sound system instrument and portable fire pump were used. The tested noise frequencies were in the range of human hearing threshold for which an equalizer instrument was used to identify the sound frequencies.

Based on this study, the rockwool absorption coefficients were 0.8, 0.96, 0.98, 0.82 for sound frequency of 500 $\mathrm{Hz}, 1000 \mathrm{~Hz}, 2000 \mathrm{~Hz}$ and $4000 \mathrm{~Hz}$ respectively. By installing the rockwool on 37.97\% of room area of $72 \mathrm{~m} 2$, this rockwool was able to reduce the noise intensity by $10.16 \mathrm{dBA}, 10.75 \mathrm{dBA}, 10.5 \mathrm{dBA}, 9.58 \mathrm{dBA}, 9.25 \mathrm{dBA}$ for frequency of $500 \mathrm{~Hz}, 1000 \mathrm{~Hz}, 2000 \mathrm{~Hz}, 4000 \mathrm{~Hz}$ and multiple frequencies respectively.

The rockwool is an effective sound absorber in noise control owing to have high absorption coefficient (almost unity) and ease for installment.

Key words : noisy, sound frequency, absorption coefficient, portable fire pump, rock wool
\end{abstract}

\section{Pendahuluan}

Kebisingan adalah merupakan salah satu dampak yang ditimbulkan oleh teknologi modern karena meningkatnya perkembangan industri yang mempunyai pengaruh luas mulai dari gangguan konsentrasi, komunikasi dan kenikmatan kerja sampai pada cacat karena kehilangan daya dengar yang menetap. Dengan demikian jelas bahwa kebisingan tidak hanya berpengaruh pada kualitas kerja tetapi berpengaruh juga pada kesehatan tenaga kerja dan masyarakat. Acuan peraturan dalam pengendalian kebisingan adalah Surat Edaran Menteri Tenaga Kerja, Transmigrasi dan Koperasi No. SE 01/MEN/1978 dan Keputusan Menteri Tenaga Kerja No. 51/MEN/1999 serta Baku Tingkat Kebisingan menurut Keputusan Meneg Lingkungan Hidup No KEP-48/MENLH/-11/96 Peruntukan Kawasan/Lingkungan Kegiatan

Pengendalian kebisingan dapat dilakukan dengan beberapa cara antara lain (Siswanto et.al, 1987) : pengendalian teknis (engineering control) baik di sumber bising, transmisi suara (sound path) dan pada si pendengarnya (receiver), pengendalian administratif (administrative scheduling control) dengan rotasi pegawai serta penggunaan alat pelindung telinga (earplug dan ear muff).

Penyerapan suara bising tergantung pada tipe permukaan penyerap serta frekuensi suaranya. Bahan yang berpori akan bersifat absorptif terhadap bising dibanding bahan yang keras yang bersifat reflektif (Gobain, 2004).

* Staf Dosen Jurusan Teknik Lingkungan Fakultas Teknik Universitas Diponegoro

**) Keselamatan Kerja dan Lingdungan Lingkungan (KKLL) Pusdiklat Migas Cepu.
Secara matematis dirumuskan sebagai berikut (Cuniff, 1977) :

$\mathrm{a}=\alpha_{1} \mathrm{~S}_{1}+\alpha_{2} \mathrm{~S}_{2}+\alpha_{\mathrm{n}} \mathrm{S}_{\mathrm{n}}$

Keterangan :

a : Sound absorption (sabin)

$\alpha$ : Koefisien serapan bahan

Beberapa bahan yang cukup absortif (nilai $\alpha>0.05$ ) diantaranya karpet, ubin akustik, tirai, rock wool sering digunakan sebagai bahan peredam kebisingan. Pengurangan kebisingan (noise reduction) didapatkan dengan mengganti/menambah material yang reflektif dengan material yang absorptif.

Adapun rumusan untuk menghitung pengurangan intensitas atau reduksi suara yang berhubungan dengan material penyerap bila ditambahkan ke suatu ruangan adalah :

$\mathrm{NR}=10 \log \left(\frac{3 \mathrm{a}+\mathrm{ag}}{\mathrm{a0}}\right)$

keterangan :

NR : Noise Reduction (dB)

ao : Orginal sound absorption (sabin)

aa : Added sound absorption (sabin)

Sebagai salah satu bahan peredam, rock wool dibuat dari bahan organik berserabut dari batu volkanis yang dipanaskan pada $1350-1400^{\circ} \mathrm{C}$ dengan batu gamping dengan tambahan coke, bahan-bahan tersebut dicairkan dan diputar ke dalam wol yang kemudian di tambah damar dan dicetak ke dalam papan cetakan. Rock wool dapat diproduksi dalam bentuk seperti kasur, papan, pipa atau sesuai kebutuhan. Rock wool mempunyai Thermal Conductivity $0.029 \mathrm{kcal} / \mathrm{mh}^{\circ} \mathrm{C}$ (pada $10^{\circ} \mathrm{C}$ ) atau 0.236 BTU-INCH/SQ.FT.H. ${ }^{\circ} \mathrm{F}$ 
(pada $50^{\circ} \mathrm{F}$ ). Suatu hasil penelitian bahan peredam dari Building Research Station yang menggunakan berbagai bahan peredam yaitu salah satunya rock wool dengan ketebalan 1 inci, memperoleh angka koefisien serapan bunyi pada frekuensi $128 \mathrm{~Hz}, 256$ $\mathrm{Hz}, 512 \mathrm{~Hz}, 1.024 \mathrm{~Hz}$ dan $4.096 \mathrm{~Hz}$ yang menghasilkan nilai koefisien serapan yang variatif dari $0.35-$ 0.83 (Sabine et.al, 1999).

Penelitian ini dilakukan untuk mengetahui nilai koefisien serapan rock wool pada frekuensi $500 \mathrm{~Hz}$, $1000 \mathrm{~Hz}, 2000 \mathrm{~Hz}$ dan $4000 \mathrm{~Hz}$. Mengetahui penurunan intensitas kebisingan yang dihasilkan oleh rock wool pada frekuensi kebisingan $500 \mathrm{~Hz}, 1000 \mathrm{~Hz}$, $2000 \mathrm{~Hz}$ dan $4000 \mathrm{~Hz}$.

\section{Metodologi}

Pengukuran tanggal 4 - 9 Oktober 2004, sedangkan tempat penelitian dilaksanakan di Bagian Keselamatan Kerja dan Lindungan Lingkungan (KKLL) Pusdiklat Migas Cepu, Jalan Sorogo No. 1 Cepu, Blora, Jawa Tengah. Dari dimensi ketebalan rock wool yang ada di pasaran $(4,5,6,10 \mathrm{~cm})$ dipilih $5 \mathrm{~cm}$ karena paling banyak digunakan. Ketahanan panas ketebalan $5 \mathrm{~cm}$ ini mencapai $1.470 \mathrm{~m}^{2} \mathrm{~K} / \mathrm{W}$.

Ruangan penelitian berdimensi pxlxt : $4 \mathrm{~m} \mathrm{x} 4 \mathrm{~m} \mathrm{x}$ $2.5 \mathrm{~m}$. Atap dan lantai : dari beton, dinding Utara batu bata pintu kaca $(2.4 \mathrm{~m} \times 0.95 \mathrm{~m})$, dinding Timur bahan batu bata jendela kaca $(1.5 \mathrm{~m}$ x $3 \mathrm{~m})$, dinding Selatan bahan batu bata jendela kaca (2.4 m x $1.5 \mathrm{~m})$ dan dinding Barat berbahan batu bata pintu : kaca 2.4 $\mathrm{m} \times 0.95 \mathrm{~m}$.

Alat pengukur kebisingan adalah SLM (Tech). Background noise diabaikan karena cukup rendah dan sudah ikut dikuantifikasi dalam perhitungan. Untuk menghasilkan frekuensi suara tertentu dipasang sound system dengan lebar frekuensi : $500 \mathrm{~Hz}, 1000$ $\mathrm{Hz}, 2000 \mathrm{~Hz}$ dan $4000 \mathrm{~Hz}$. Sound system ini dilengkapi dengan VCD player, amplifier, equalizer dan salon. Untuk menghasilkan frekuensi campuran (seperti alat pada umumnya) digunakan portable fire pump (Godiva 100 GPM). Titik pengukuran untuk di dalam ruangan ditentukan 1 meter dari setiap sisi dinding, sedang diluar ruangan 3 meter dan 5 meter dari setiap sisi dinding. Jumlah sampel baik di dalam maupun di luar ruang sebanyak 12 buah untuk setiap frekuensi suara sebelum dan sesudah pemasangan rock wool khusus pada dinding ruangan. Sekeliling dinding dipasang rock wool kecuali bagian jendela dan pintu. Secara keseluruhan, luasan peredaman mencapai $38 \%$ dari total luas dalam ruang. Setiap sampel diambil tiga kali (triplo). Hasil dari pengukuran tiap sisi ruang tidak diekivalenkan karena pengukuran tidak secara simultan dilakukan, sebagai gantinya dilakukan perata-rataan kebisingan. Total waktu pengukuran bising mencapai 120 menit untuk setiap perlakuan.

\section{Analisis Dan Pembahasan}

Hasil pemantauan kebisingan ditampilkan dalam perhitungan sound absorption, koefisien serapan rock wool. Untuk mengetahui pengaruh pemasangan rock wool dalam peredaman kebisingan maka kondisi awal perlu diketahui. Background noise setelah diukur relative tidak terdeteksi, sehingga dalam perhitungan nantinya tidak secara eksplisit memasukkan faktor background noise.

\section{Kebisingan awal}

Sebelum dilakukan pemasangan rock wool dilakukan pemantauan kebisingan yang menghasilkan data sesuai tabel 1, tabel 2 dan tabel 3.

Nilai kebisingan indoor yang diperoleh didapat ratarata diatas baku kebisingan untuk industri sebesar 70 dBA. Kebisingan di luar ruangan pada jarak $3 \mathrm{~m}$ mencapai $43-45 \%$ lebih rendah dibanding di dalam ruang. Sedang pada jarak $5 \mathrm{~m}$ kebisingan telah tereduksi 48-49\%. Reduksi terbesar ada di frekuensi rendah yaitu $500 \mathrm{~Hz}$ walaupun selisihnya tidak terlampau jauh dengan frekuensi diatasnya. Hal ini disebabkan dinding memiliki faktor absorptivitas yang baik pada frekuensi rendah.

Tabel 1. Hasil Pengukuran Awal Kebisingan di Dalam Ruang

\begin{tabular}{|c|c|c|c|c|c|}
\hline Frek & $\mathrm{U}$ & $\mathrm{T}$ & $\mathrm{S}$ & $\mathrm{B}$ & Avg \\
\hline $\mathrm{Hz}$ & \multicolumn{5}{|c|}{$\mathrm{dBA}$} \\
\hline 500 & 96.67 & 97.33 & 96.67 & 96.67 & 96.83 \\
1000 & 100.67 & 101.33 & 100.67 & 100.33 & 100.75 \\
2000 & 93.33 & 93.67 & 94.33 & 93.67 & 93.75 \\
4000 & 90.00 & 90.33 & 90.33 & 90.33 & 90.25 \\
\hline
\end{tabular}

Tabel 2. Hasil Pengukuran Awal Kebisingan di Luar Ruang

\begin{tabular}{|c|c|c|c|c|c|}
\hline Frek & $\mathrm{U}$ & $\mathrm{T}$ & $\mathrm{S}$ & $\mathrm{B}$ & Avg \\
\hline $\mathrm{Hz}$ & \multicolumn{6}{|c|}{$3 \mathrm{~m}$} \\
\hline \multicolumn{6}{|c|}{} \\
\hline 500 & 52.67 & 52.00 & 52.67 & 54.33 & 52.92 \\
1000 & 55.33 & 55.67 & 56.67 & 57.33 & 56.25 \\
2000 & 52.33 & 52.33 & 52.67 & 53.33 & 52.67 \\
4000 & 50.33 & 50.33 & 50.67 & 51.33 & 50.67 \\
\hline \multicolumn{6}{|c|}{$5 \mathrm{~m}$} \\
\hline 500 & 48.67 & 48.00 & 49.00 & 50.33 & 49.00 \\
1000 & 50.67 & 51.67 & 52.33 & 50.67 & 51.33 \\
2000 & 47.67 & 47.33 & 47.67 & 48.33 & 47.75 \\
4000 & 47.00 & 45.67 & 46.00 & 48.33 & 46.75 \\
\hline
\end{tabular}

Untuk sumber multi frekuensi didapat:

Tabel 3. Hasil Pengukuran Awal Kebisingan Multi Frekuensi

\begin{tabular}{|c|c|c|c|c|c|}
\hline Tempat & $\mathrm{U}$ & $\mathrm{T}$ & $\mathrm{S}$ & $\mathrm{B}$ & Avg \\
\hline & \multicolumn{5}{|c|}{ DBA } \\
\hline Indoor & 87.33 & 88.33 & 86.67 & 87.33 & 87.42 \\
\hline Outdoor & 49.00 & 48.67 & 49.67 & 50.33 & 49.42 \\
\hline
\end{tabular}


Hasil pengukuran untuk sumber multi frekuensi untuk di dalam ruang masih lebih tinggi dibanding standar baku tingkat kebisingan yaitu $70 \mathrm{dBA}$.

Secara umum tingkat kebisingan paling tinggi terdapat di sisi Barat, hal ini terjadi karena permukaan reflektifnya lebih banyak dibanding sisi lainnya. Disamping itu arah outlet kebisingan alat juga menentukan letak kebisingan.

\section{Kebisingan setelah ada peredaman}

Secara umum terjadi penurunan tingkat kebisingan setelah ada pemasangan rock wool di sekeliling dinding ruang.

Reduksi kebisingan di luar ruang pada jarak $3 \mathrm{~m}$ dan $5 \mathrm{~m}$ setelah ada pemasangan rock wool masing-masing mencapai $50 \%$ dan 55\%. Nilai reduksi ini lebih tinggi dibanding pada kondisi kebisingan awal. Hal ini disebabkan oleh pengaruh rock wool ikut menghambat prosentase kebisingan yang diteruskan ke luar ruang.

Tabel 4. Hasil Pengukuran Kebisingan di Dalam Ruang Setelah Dipasang Rock Wool

\begin{tabular}{|c|c|c|c|c|c|}
\hline Frek & $\mathrm{U}$ & $\mathrm{T}$ & $\mathrm{S}$ & $\mathrm{B}$ & Avg \\
\hline $\mathrm{Hz}$ & \multicolumn{5}{|c|}{$\mathrm{dBA}$} \\
\hline 500 & 86.67 & 87.33 & 86.67 & 86.00 & 86.67 \\
1000 & 89.67 & 90.33 & 90.33 & 89.67 & 90.00 \\
2000 & 82.67 & 83.67 & 83.33 & 83.33 & 83.25 \\
4000 & 80.00 & 80.67 & 81.33 & 80.67 & 80.67 \\
\hline
\end{tabular}

Tabel 5. Hasil Pengukuran Kebisingan di Luar Ruang Setelah Dipasang Rock Wool

\begin{tabular}{|c|c|c|c|c|c|}
\hline Frek & $\mathrm{U}$ & $\mathrm{T}$ & $\mathrm{S}$ & $\mathrm{B}$ & Avg \\
\hline $\mathrm{Hz}$ & \multicolumn{6}{|c|}{$3 \mathrm{~m}$} \\
\hline \multicolumn{7}{|c|}{} \\
\hline 500 & 42.33 & 42.67 & 43.33 & 43.33 & 42.92 \\
1000 & 44.67 & 44.00 & 44.67 & 45.33 & 44.67 \\
2000 & 41.67 & 41.00 & 41.67 & 42.33 & 41.67 \\
\hline 4000 & 40.33 & 40.33 & 40.33 & 40.33 & 40.33 \\
\hline \multicolumn{7}{|c|}{$5 \mathrm{~m}$} \\
\hline Frek & $\mathrm{U}$ & $\mathrm{T}$ & $\mathrm{S}$ & $\mathrm{B}$ & Avg \\
\hline $\mathrm{Hz}$ & $\mathrm{dBA}$ \\
\hline 500 & 39.67 & 39.33 & 39.67 & 40.33 & 39.75 \\
1000 & 40.67 & 40.67 & 41.67 & 42.33 & 41.33 \\
2000 & 37.33 & 36.67 & 36.67 & 37.33 & 37.00 \\
4000 & 36.67 & 36.33 & 36.67 & 37.33 & 36.75 \\
\hline
\end{tabular}

Tabel 6. Hasil Pengukuran Kebisingan Multi Frekuensi Setelah Dipasang Rock Wool

\begin{tabular}{|c|c|c|c|c|c|}
\hline Tempat & $\mathrm{U}$ & $\mathrm{T}$ & $\mathrm{S}$ & $\mathrm{B}$ & Avg \\
\hline & \multicolumn{5}{|c|}{$\mathrm{dBA}$} \\
\hline Indoor & 52.67 & 52.00 & 52.67 & 53.33 & 52.67 \\
Outdoor & 41.67 & 42.33 & 42.33 & 41.33 & 41.92 \\
\hline
\end{tabular}

Penurunan kebisingan di dalam ruang karena pemasangan rock wool mencapai rata-rata $10.75 \%$, sedang di luar ruang untuk jarak $3 \mathrm{~m}$ dan $5 \mathrm{~m}$ masing-masing terjadi penurunan sebesar $20.19 \%$ dan $20.57 \%$. Hasil reduksi pada multi frekuensi terjadi lebih besar lagi yaitu rata-rata $27.46 \%$. Nilai - nilai diatas masih lebih kecil dibanding reduksi pada keadaan awal (antara indoor dan outdoor). Dari uraian diatas bisa diambil kesimpulan bahwa reduksi kebisingan dengan adanya pembatas dinding dan pemberian jarak antara sumber dan penerima jauh lebih efektif dibanding melakukan peredaman di ruang tempat terjadi kebisingan dengan rock wool.

\section{Koefisien Serapan Rock Wool}

Untuk menghitung koefisien serapannya maka persamaan (2) sedikit diubah menjadi :

$\alpha 2=\frac{a a}{\text { total luas dinding }}+a 1$

NR : Noise Reduction (dBA)

ao : Orginal sound absorbtion (Sabin)

aa : Added sound absorbtion (Sabin)

$\alpha 2$ : Koefisien serapan rock wool

$\alpha 1$ : Koefisien serapan bahan yang diredam (dinding)

Koefisien serapan dapat dihitung sebagai berikut (contoh untuk frekuensi $500 \mathrm{~Hz}$ ) :

Luas permukaan yang ada di dalam ruang adalah sebagai berikut : atap $16 \mathrm{~m}^{2}$, lantai $16 \mathrm{~m}^{2}$, dinding $27.34 \mathrm{~m}^{2}$, pintu dan jendela $12.66 \mathrm{~m}^{2}$. Koefisien serapan bahan dalam ruang penelitian yang terdiri atas beton, batu bata, kaca dalam rentang frekuensi penelitian ini didapat dari literatur (May et.al, 1978). Sehingga berdasar persamaan (1) didapat nilai ao = 2.26 Sabin. Penurunan kebisingan (NR) berdasar percobaan adalah $10.16 \mathrm{dBA}$. Menurut literatur, koefisien serapan dinding batu bata (dalam hal ini $\alpha 1$ ) bernilai 0.02. Sehingga berdasar persamaan (3) nilai $\alpha 2$ : 0.8 . Dengan cara yang sama didapat koefisien serapan untuk $1000 \mathrm{~Hz}, 2000 \mathrm{~Hz}$ dan 4000 Hz masing-masing 0.96, 0.98 dan 0.82.

Sehingga nilai umum koefisien serapan rock wool dapat diestimasi dari grafik dibawah ini.

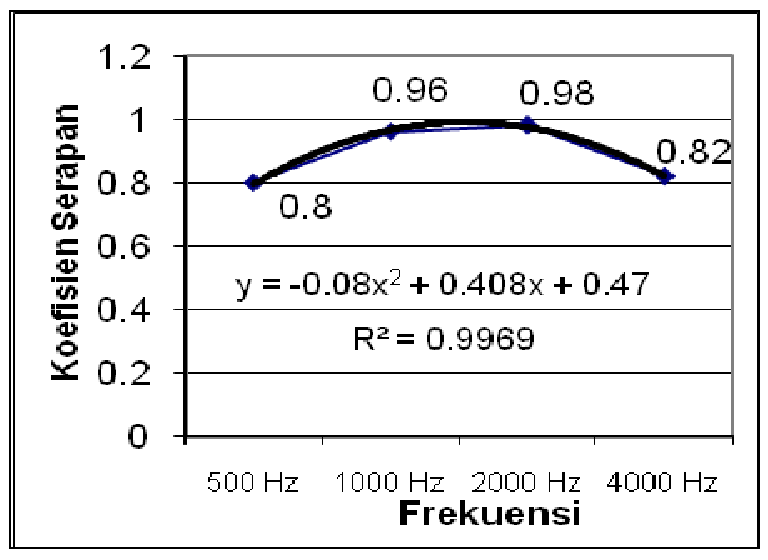

Gambar 1. Estimasi Koefisien Serapan

Rock Wool pada frekuensi $500 \mathrm{~Hz}, 1000$ $\mathrm{Hz}, 2000 \mathrm{~Hz}$ dan $4000 \mathrm{~Hz}$ 
Dari gambar grafik terlihat bahwa koefisien serapan rock wool pada frekuensi rendah $(<500 \mathrm{~Hz})$ dan freku-nsi tinggi $(>4000 \mathrm{~Hz})$ memiliki serapan bunyi yang lebih rendah dibanding pada frekuensi $500 \mathrm{~Hz}-$ $4000 \mathrm{~Hz}$, hal ini disebabkan karena penyerapan suatu bahan peredam akan mencapai suatu batas maksimum yang terjadi pada frekuensi gema/resonance frequency (Gobain, 2002).

\section{Kesimpulan}

Angka koefisien serapan rock wool dengan ketebalan $5 \mathrm{~cm}$ untuk frekuensi $500 \mathrm{~Hz}$ adalah 0.8 dan untuk frekuensi $1000 \mathrm{~Hz}$ adalah 0.96, sedangkan untuk frekuensi $2000 \mathrm{~Hz}$ adalah 0.98 dan untuk frekuensi $4000 \mathrm{~Hz}$ adalah 0.82. Penurunan intensitas kebisingan yang dihasilkan dari pemasangan rock wool dengan ketebalan $5 \mathrm{~cm}$ dengan $37.97 \%$ peredaman yaitu untuk frekuensi $500 \mathrm{~Hz}, 1000 \mathrm{~Hz}, 2000 \mathrm{~Hz}$ dan $4000 \mathrm{~Hz}$ berturut-turut adalah $10.16 \mathrm{dBA}, 10.75$ dBA, $10.5 \mathrm{dBA}$ dan $9.58 \mathrm{dBA}$. Penurunan intensitas kebisingan yang dihasilkan dari pemasangan rock wool dengan ketebalan $5 \mathrm{~cm}$ terhadap suara portable fire pump (salah satu contoh jenis peralatan industri) yang mempunyai gabungan dari berbagai frekuensi adalah sebesar $27.46 \%$.

\section{Saran}

Penggunaan rock wool dalam reduksi kebisingan dari penggunaan berbagai peralatan di dunia industri perlu diperhatikan ketebalan rock wool agar dapat mendapatkan hasil yang optimal. Hal ini mengingat harga rock wool yang masih mahal untuk diaplikasikan di setiap ruang yang ada sumber kebisingannya.

\section{Ucapan Terimakasih}

Penulis mengucapkan terimakasih kepada pihak Pusdiklat Migas Cepu atas bantuan fasilitas untuk pengukuran pengambilan data.

\section{Daftar Pustaka}

1. Caner Company, 2002, Wellcome to the Caner Co Ltd. Website, www. Caner Ltd. Com / Tasyumen. htm. (tgl.29 November 2004)

2. Cunniff, Patrick ., 1977, Environmental Noise Pol-lution, John Wiley \& Sons, New York

3. Gobain, Saint, 2004, Isover : Rock Wool Insulation, www.Isover Com / acoustic_ins / rw ins. htm. (tgl. 30 November 2004)

4. Harris, C.M, 1979, Handbook of Acoustical Measurements and Noise Control, Mc. Graw-Hill Book Co.,New York.

5. May, D, 1978, Handbook of Noise Assessment, Van Nostrand Reinhold Company, New York

6. Pelton, H.K., 1993, Noise Control Management, Van Nostrand Reinhold Company, New York.

7. Sears Francis Weston, 1991, Mekanika Panas dan Bunyi, Binacipta, Bandung

8. Reamer, de Russel, 1980, Modern Safety and Health Technology, John Willey and Sons, Canada.

9. Richard, K.M dan V.M. Wayne, 1978, Handbook of Acoustic Enclosures and Barriers. The Fairmont Press, Inc.
10. Sabine, Wallace, 1999, Building Research Station England, www 2 sfu.ca / sonic.studio / hand book / absorption coef.html. (tgl. 30 November 2004)

11. Siswanto, A, Haryuti, Ir dan Agustin Idayanti T, Dr, 1987, Kebisingan, Depnaker Balai Hiperkes, Surabaya. 